\title{
EL SISTEMA URUGUAYO DE RELACIONES LABORALES: ENTRE AUTONOMÍA Y NEGOCIACIÓN
}

\author{
JUAN RASO DELGUE* \\ Universidad de la República, Uruguay
}

\begin{abstract}
RESUMEN: En este artículo se aborda desde una perspectiva histórica el desarrollo del modelo de relaciones de trabajo en la República de Uruguay, abordando desde sus inicios como República independiente hasta la situación actual. Se describen las características de cada período, analizando sus hitos en materia de regulación laboral, los programas de los distintos gobiernos que se han sucedido en el poder. $\mathrm{El}$ autor aprecia que el carácter sui generis del modelo de relaciones laborales uruguayo, tiene como eje dos extremos: el liberal de mercado y el intervencionista, ante este estado de la cuestión, el autor se manifiesta partidario de la intervención, pues ha dado un cauce para la resolución pacífica de los conflictos.
\end{abstract}

Palabras clave: Derecho del Trabajo uruguayo, Consejo de salarios, empleo, responsabilidad social, políticas públicas, sindicatos, negociación, diálogo social.

ABSTRACT: This article discusses, from a historical perspective, the development of the model of labor relations in the Republic of Uruguay, addressing since its origins as an independent republic until the current situation. Tha author describes the characteristics of each period, analyzing its milestones in labor regulation, the programs of the various governments that have succeeded in power. The author shows that the sui generis character of the Uruguayan labor relations model has two extremes: the liberal market-oriented one and the interventionist one; to this state of affairs, the author states in favor of the intervention, because it has given a channel for the peaceful resolution of conflicts.

Key words: Uruguayan Labor law, Salary Counsel, employment, social responsibility, public policies, sindicates, negotiation, social dialogue.

\section{CONTEXTO GEOGRÁFICO, HISTÓRICO Y HUMANO}

Uruguay, el país más pequeño de América del Sur con una superficie de 177.000 $\mathrm{km}^{2}$, alcanza una población de aproximadamente 3.160 .000 habitantes. Es un país con una alta tasa de urbanización $(87,3 \%)$ y la mitad de la población reside en la capital Montevideo. La Población Económicamente Activa (PEA) es de 1.440.489 habitantes.

Su tasa de crecimiento es baja $(0,6 \%)$, alto porcentaje de alfabetización $(96,9 \%)$ y la población es de raza blanca, con escaso índice de presencia negra y ausencia de indígenas. Puede definirse como una población muy homogénea e integrada, producto de emigraciones desde distintos países europeos (con alta predominancia española e italiana) ${ }^{1}$.

A diferencia de otros países latinoamericanos, la cultura precolombina no perduró luego de la colonización y la independencia. Figuras históricas que identifican la identidad nacional son Artigas, caudillo republicano, federalista, democrático, con una visión social y popular (impulsor de un proyecto de reforma agraria) y José Pedro Varela, reformador de la escuela y promotor de la educación gratuita, laica y obligatoria.

\footnotetext{
Catedrático de Derecho del Trabajo y de Relaciones Laborales de la Facultad de Derecho, Universidad de la República, Montevideo, Uruguay.

1 Relasur/OIT, Las relaciones laborales en Uruguay, Madrid 1995.
} 
El país comienza a desarrollarse a mitad del siglo XIX a partir de la llegada de un importante flujo inmigratorio, que iniciará el proceso de industrialización y urbanización. A comienzos del siglo XX debe destacarse la doble presidencia de José Batlle y Ordóñez (1903 a 1907 y 1911 a 1915) por su especial influencia en la modernización del país. Es en este periodo que se desarrolla una concepción de Estado de bienestar social que adelanta las concepciones del Welfare State de la segunda posguerra europea. Se desarrolla un modelo social, económico y político, caracterizado por una fuerte presencia estatal, ya sea en el plano económico (creación de empresas públicas de carácter financiero e industrial), que en el social. Comienza un periodo de prosperidad que se consolidará a través de un verdadero pacto social de carácter informal entre los actores del sistema: los sindicatos reclamarán mejores condiciones de trabajo a través del conflicto-negociación; a su vez las concesiones de las empresa en materia de salario y condiciones de trabajo serán compensadas por el Estado, a través de una política arancelaria de protección a la industria nacional.

El modelo se agota a fines de los años 50 y durante la década del 60 se acelera un proceso de crisis (deterioro internacional de los precios de las materias primas, inflación monetaria, endeudamiento con el exterior) que concluirá en el golpe de estado de junio de 1973.

La reinstitucionalización democrática en 1985 intentará por pocos años reconstruir el modelo social anterior, fundamentalmente a través de la convocatoria de los Consejos de Salarios (organismos tripartitos diferenciados por áreas de actividad para la regulación concertada de los salarios), pero a partir de 1992 el país se alinea en las tendencias neoliberales, influenciado además por las fuertes presiones externas en una economía globalizada ${ }^{2}$.

En marzo de 2005 la coalición de izquierda Frente Amplio asume por primera vez el gobierno y aplica su propuesta política de sustituir el modelo neoliberal, por un modelo de crecimiento económico con distribución social.

Digamos finalmente que en la actualidad, el trabajo de la PEA -formal e informalestá concentrado fundamentalmente en el área de los servicios (67\%), mientras se reduce la presencia en el sector industrial o secundario (23\%) y en el sector primario (10\%).

\section{LA EVOLUCIÓN DE LA NORMATIVA LABORAL}

Podemos dividir la evolución histórica de la normativa laboral en diferentes períodos:

\subsection{EL PERIODO FUNDADOR (HASTA 1930)}

Como recuerda Barbagelata, en los primeros años del siglo XX se dictan diferentes normas, relativas a la reglamentación general de la prestación de trabajo (la ley llamada de las ocho horas y el régimen descanso semanal), reglamentaciones especiales (la ley de la silla que obligaba a los patrones a proporcionar una silla a las mujeres que trabajaban, la prohibición del trabajo nocturno en las panaderías, el Código Rural), normas de previsión social (bases para un régimen de jubilaciones generales en la actividad privada, ley de accidentes de trabajo), normas de contralor (organización de la Oficina Nacional de Trabajo, con funciones de asesoramiento e inspección).

2 ERMIDA URIARTE, O. Apuntes sobre la Evolución Histórica del Derecho Laboral en Uruguay (inédito). 
2.2. El DESARrollo (1930 - 1950)

De este período, destacamos:

1. La constitucionalización del trabajo como derecho fundamental y de la protección y promoción de los derechos de los trabajadores (1934).

2. La ratificación de los primeros Convenios Internacionales de la OIT (1933).

3. La sanción del Código del Niño, que reguló el trabajo de los menores (1934).

4. La aprobación de textos legales fundamentales: la ley de fijación de salarios mínimos (1943), las leyes de indemnización por despido (1944) y la ley de vacaciones anuales (1944), el estatuto del trabajador rural (1946).

En este período se va consolidando el derecho del trabajo nacional, a través de una red normativa que -a decir de Barbagelata- produce los siguientes efectos:

- mejoramiento de la situación de las clases obreras, con aumento de los salarios reales;

- aumento de la seguridad en el empleo;

- democratización del ocio, al generalizarse el régimen de vacaciones anuales;

- $\quad$ estímulo de la organización sindical y limitación del absolutismo patronal;

- creación de mecanismos para la clasificación, evaluación y definición de las tareas en las diferentes ramas de actividad industrial y no industrial;

- promoción del tripartismo a través de las mesas negociadoras de los consejos de salarios, donde se discutían las desinteligencias obrero-patronales.

\subsection{LA CONSOLIDACIÓN (1950 - 1968)}

Se destaca en este período:

1. El reconocimiento del derecho de huelga de los funcionarios públicos en la Constitución de 1952.

2. La consolidación de la normativa protectora del contrato de trabajo, a través de la aprobación de nuevas leyes relativas al trabajo insalubre (1950), seguro de desempleo (1952), ratificación de nuevos Convenios Internacionales del Trabajo (1953), jubilaciones (1954), jornada (1957), indemnización por despido (1957), licencia (1958), sueldo anual complementario (1960), proceso laboral (1960), accidentes de trabajo (1961), convenios colectivos (1966).

Como ha señalado Ermida, en este período hay un gran avance en la doctrina nacional, con los aportes de De Ferrari, Plá Rodríguez y Barbagelata y una influencia importante de los partidos políticos, los sindicatos y los demás grupos de presión. Ello determina que las leyes generalmente se aprueban en años electorales y también que se vaya construyendo 
Juan Raso Delgue / El sistema uruguayo de relaciones laborales: entre autonomia y negociación

una legislación fragmentada, que otorga mayores beneficios -especialmente en materia de seguridad social- a los sectores más organizados.

\subsection{LA CRISIS Y LA SUBORDINACIÓN DE LO SOCIAL A LO ECONÓMICO (1968 A 1985)}

El proceso de crecimiento de la economía uruguaya comenzó -como se adelantó- a desacelerarse a fines de los años 50 y se detuvo en los años 60 . Factores exógenos y endógenos al sistema -que no podemos analizar en la brevedad de este trabajo- determinaron un estancamiento productivo y la aparición del fenómeno de la inflación que marcaría los años siguientes. También se produce un cambio de mentalidad en las dirigencias políticas y los objetivos sociales que había caracterizado el modelo, son sustituidos por objetivos económicos: a partir de 1968 el gobierno comienza a seguir criterios neoliberales, aunque en la época aún no se calificaran como tales.

El 28 de junio de 1968 se dicta un decreto de "congelación" de salarios, que significará en lo laboral un cambio radical: el pasaje de un sistema de consenso a un modelo laboral fuertemente dirigido por el Estado. Este fenómeno se acentuará a partir del golpe de estado militar de 1973: las primeras medidas del gobierno de facto estarán destinadas a suprimir lisa y llanamente el derecho colectivo del trabajo, cerrando los sindicatos y encarcelando a sus dirigentes.

En este periodo, se dictan normas sobre seguridad social (eliminando una importante experiencia de gestión tripartita desarrollada en las dos décadas anteriores), se dictan normas violatorias de la libertad sindical y se dicta (a nuestro juicio, única norma de signo positivo) la ley $\mathrm{N}^{\circ} 14.188$ sobre procedimiento laboral.

\subsection{LA REINSTITUCIONALIZACIÓN DEMOCRÁTICA (1985)}

En 1985, al restablecerse el régimen constitucional, se recompone en materia laboral la red normativa de tutelas ya sea a nivel individual como colectivo. La nueva política salarial, con la convocatoria de los Consejos de Salarios (inoperantes desde 1968), permite una recuperación de los salarios reales.

En materia legislativa se dictan normas sobre prescripción de los créditos laborales, igualdad de trato y oportunidades para ambos sexos, modificaciones al régimen de accidentes de trabajo y enfermedades profesionales, elevación y generalización a toda la actividad privada de las llamadas sumas para el mejor goce de la licencia.

\subsection{EL PERIOODO NEOLIBERAL (1992-2005)}

En el año 1992 el Poder Ejecutivo deja de convocar los Consejos de Salarios, mientras se produce una involución en la protección laboral. El creciente desempleo y la crisis sindical determinan que los trabajadores comiencen a aceptar condiciones laborales menos beneficiosas (más allá de lo discutible que es la renuncia de derechos adquiridos), bajo el temor de perder sus puesto de trabajo.

El proceso flexibilizador es menos ostentoso que en otros países -lo que permite hablar a Rosenbaum y Garmendia de el discreto proceso uruguayo de reforma laboral-, pero sus consecuencias en las condiciones salariales y laborales son evidentes. Sin introducir normas "expresamente" flexibilizadoras, dos elementos han provocado la flexibilización de hecho: 
a) la ya indicada política salarial emprendida por el Estado a partir de 1992, lo cual ha determinado que hoy más del $80 \%$ de los salarios se negocian a nivel individual, donde el trabajador tiene muy poco poder de contratación; b) la reducción drástica de los términos de prescripción (de 10 a 2 años) significa en los hechos un blanqueo de toda irregularidad laboral más allá de ese plazo.

\subsection{UN NUEVO MODELO SOCIAL $(2005$ - ...)}

La crisis económica de 2002 , la polarización social cada vez más marcada, la declinación de un bipartidismo político (partidos Blanco y Colorado) que no había sabido dar respuestas a los reclamos de la sociedad, confluyen en la amplia victoria en octubre de 2004 de la coalición de izquierda Frente Amplio-Encuentro Progresista, que asumirá el gobierno el primero de marzo de 2005.

La coalición, presidida por el médico Tabaré Vázquez, promoverá desde el mismo momento de la asunción al poder una serie de políticas públicas destinadas a revertir la herencia recibida del período neoliberal: extensa marginalización y pobreza, crisis sindical, deterioro de los salarios, pérdida de centralidad de instituciones que habían caracterizado el país en los años 50 y 60 como la enseñanza, la salud pública y la seguridad social.

En la aplicación de los nuevos planes políticos, el Gobierno recurrió a un mecanismo, que siempre marcó los momentos mejores de la vida del país: el tripartismo. En efecto, una característica de las políticas públicas en el Uruguay siempre fue la presencia del tripartismo, entendido como participación estructurada de los actores sociales (Estado, trabajadores y empleadores) en aquellas reglas y decisiones vinculadas al sistema de relaciones laborales y tutelas sociales.

Si bien el tripartismo era una característica del sistema ya a mitad del siglo pasado, la nueva orientación política del gobierno ha permitido una consolidación y expansión de la intervención de los tres actores sociales a través de un proceso activo de diálogo social.

Es importante destacar esta vinculación entre "políticas públicas" y "diálogo social", porque consideramos que las políticas públicas deben nutrirse de diálogo social. Solo la persuasión y el acuerdo de las partes pueden promover situaciones estables en el sistema. En este sentido la vinculación entre las partes, aunque signifique un camino más lento y dificultoso, permite superar las diferencias ideológicas y construir una nueva cultura que ponga en el centro del debate el concepto de "trabajo decente" 3 .

Consideramos que en la presente instancia la promoción del diálogo social es en sí mismo una "política pública" del actual gobierno. El desarrollo social de un sistema de relaciones laborales debe construirse sobre un justo equilibrio entre las demandas económicas.y la cohesión social. Las políticas públicas no solo tienen que atender al progreso económico, sino que deben en especial preocuparse que ese "progreso" llegue a todos 4 .

\footnotetext{
3 Fernandez Brignoni, H., Santestevan A. y Rodríguez J. M. Concepto y Medición del Trabajo Decente. Informe Uruguayo al X Encuentro de Ex Becarios de Bologna-Castilla La Mancha. Punta del Este, Uruguay, 2001.

4 Garmendia M. Actualidad y perspectivas del Derecho del Trabajo en América Latina. Conferencia dictada en la Universidad de Campinhas, Estado de San Pablo - Brasil, 15 de febrero de 2008.
} 


\section{LOS ACTORES SOCIALES}

\subsection{EL ESTADO}

El gobierno que asumió en el año 2005 le dio un nuevo impulso al rol del Estado en el sistema de relaciones laborales, pasando de un "Estado prescindente" a un "Estado comprometido en el sistema”.

Entre las decisiones tomadas desde la nueva conducción debe señalarse:

\section{a) La convocatoria de los Consejos de Salarios}

La ley 10.490 -una vieja ley aprobada en el año 1943- disponía la formación de consejos tripartitos de salarios por cada sector de la actividad privada. De este modo se constituyeron a partir de la vigencia de la ley aproximadamente 50 grupo (el número nunca fue exacto y obedeció a las cambiantes circunstancias del sistema), en los que se dividió toda la actividad privada. Cada grupo, formado por tres representantes del gobierno, dos de los empleadores y dos de los trabajadores, debía determinar los salarios mínimos, los aumentos y las categorías laborales.

En la época de la dictadura militar (1973 a 1985) y en la época de los gobiernos neoliberales (1992 a 2004) se suspendieron los Consejos de salarios. A partir del mes de mayo de 2005 se organizaron de nuevo los Consejos, dividiendo ahora toda la actividad privada en 20 grupos, cada uno de los cuales podía dividirse en diferentes subgrupos.

La nueva presencia de los Consejos de salarios en el sistema de relaciones laborales ha tenido como principal consecuencia una reoxigenación de todo el sistema, porque las continuas negociaciones a nivel institucional han fortificado al movimiento sindical y han permitido promover una negociación continua entre empleadores y trabajadores -con intervención del Estado- en materias tan importantes como las categorías laborales y la fijación de los salarios a nivel de las diversas actividades.

Esta nueva política en materia de salario ha modificado radicalmente el alicaído sistema de relaciones laborales del período 1992 a 2004 y ha puesto nuevamente el trabajo como tema central del debate político nacional, ha promovido la participación responsable de los actores y ha obtenido como resultado -y contra las previsiones de los pesimistas- una negociación exitosa.

Las decisiones negociadas de los Consejos no se han limitado a los salarios y las categorías: en los diversos acuerdos suscritos por las partes, se han también negociado temas importantes y actuales como la productividad, la capacitación, la competitividad, el rediseño de las funciones y competencias, las condiciones de trabajo (incluyendo el medio ambiente interno y externo a la empresa).

Debe señalarse además que el rol activo de los Consejos de salarios cumple con los preceptos contenidos en las normas de la OIT en materia de fijación de salarios mínimos. (Ver Declaración de Principios y Derechos Fundamentales del año 1998 y Convenios Internacionales de Trabajo $N^{\circ} 26,99$ y 131). 


\section{La promoción de la libertad sindical}

En el período 1992 a 2004 el modelo de desregulación laboral había provocado una amplia crisis sindical, que se agravó en la crisis económica del 2002 con altos índices de desempleo y rebaja de salarios. La situación se había vuelto tan difícil para las organizaciones, que -como ya dijimos- muchas de ellas ante la presión de las circunstancias económicas, comenzaron a negociar convenios colectivos in pejus.

Uno de los principales propósitos del Gobierno que asumió el poder en marzo de 2005 fue el de impulsar políticas públicas de promoción de la actividad sindical. La actividad de los Consejos de Salarios, a la que ya nos hemos referidos, favoreció la recomposición de los sindicatos en torno a las nuevas estrategias de negociación colectiva. Pero se consideró que ello no era suficiente y se aprobó una ley para tutelar la libertad sindical, derecho que se consideró necesario proteger para que la negociación colectiva operara en un ambiente de igualdad de partes.

Es así que el 2 enero de 2006 se aprobó la ley 17.940, cuyas principales reglas establecieron:

- La nulidad absoluta de toda discriminación que menoscabe la libertad sindical, lo cual introduce el concepto de estabilidad absoluta en el trabajo de todo militante sindical (dirigente o simple trabajador);

- Derecho a la licencia sindical, a los efectos que los dirigentes sindicales puedan disponer de tiempo suficiente para ejercer su actividad;

La retención de la cuota sindical, que permite a los sindicatos recaudar mayores fondos para su actividad;

Facilidades para proselitismo sindical en la empresa, con normas relativas a cartelera sindical, distribución de material informativo, etc.

La ley ha permitido fortalecer la presencia de los sindicatos en el sistema de relaciones laborales, estableciendo sanciones para el empleador que discrimina a los representantes sindicales y al mismo tiempo normas de promoción interna de los sindicatos, que han favorecido una más fluida negociación colectiva.

\section{c) La inversión en la enseñanza pública}

Uno de los planes de Gobierno ha apostado por una mayor inversión en la enseñanza pública y la promoción de una política de modernización y adecuación a las necesidades de formación de todos los sectores de la sociedad. Para ello se instrumentó un plan participativo que incluyera una "mayor inversión económica a la educación pública". En el año 2004 la inversión en la educación pública no superaba el 2,2\% y el objetivo anunciado por el nuevo gobierno para el final de su gestión (2009) es el de elevar el gasto al 4,5\% del PIB. $\mathrm{Al}$ mismo tiempo se ha abierto un gran debate educativo con la participación de los diversos actores del sistema (autoridades, docentes, estudiantes, personal técnico) para definir las prioridades y las innovaciones a impulsar en el quinquenio 2005-2009 y establecer las transformaciones más profundas a mediano y largo plazo. 
Las nuevas políticas públicas en materia de educación tienen como objetivo acercar la enseñanza teórica y las necesidades de trabajo del mercado laboral. Por tal motivo a nivel de enseñanza terciaria existe la voluntad de promover carreras "cortas" que permitan una rápida inserción laboral. En los proyectos de carreras "cortas" está presente la necesidad de ofrecer formaciones rápidas a los futuros trabajadores, pero con la idea de que una formación rápida es solo una etapa en un proyecto de formación a lo largo de toda la vida.

\section{d) La consolidación en materia de creación de empleo}

Una interesante experiencia en materia de políticas activas de empleo promovidas desde el sector público ha sido la Junta Nacional de Empleo (JUNAE), organismo tripartito que fue instituido por la Ley 16.320 de 1.XI.1992, al que el nuevo Gobierno ha dado un impulso mayor con la creación del INFOP (Instituto de Formación Profesional), integrado tripartitamente. Su principal cometido es el de administrar el Fondo de Reconversión Industrial: este fondo se constituye con aportes de los empleadores y trabajadores y se administra fundamentalmente para organizar planes de formación y capacitación para trabajadores desocupados o para empresas o sectores que acuerden planes de capacitación. Para realizar estas actividades la DINAE puede contratar organismos públicos o entidades privadas que se dediquen a la capacitación laboral (Ej., escuelas de hotelería, de computación, de idiomas, etc.).

Actualmente los planes de formación se llevan adelante a través de diferentes Programas, entre los que destacamos:

- Programa para Trabajadores en Seguro de Desempleo (TSD)

- Programa de Capacitación para Jóvenes (PROJOVEN)

- Programa para personas con Discapacidad (PROCLADIS)

- Programa de Capacitación para Mujeres (PROMUJER)

\section{e) La promoción de la "responsabilidad social de la empresa" (RSE)}

Desde el gobierno se impulsan iniciativas para incluir en la agenda de las políticas públicas la cuestión de la RSE.

Una de las propuestas que se plantea desde el Ministerio de Desarrollo Social (MIDES) es la convocatoria a empresas para que integren programas de inclusión de trabajadores, recibiendo a cambio beneficios como, por ejemplo, un mejor posicionamiento ante las licitaciones del Estado. "Lo que sí hay que generar - se ha expresado a nivel de gobierno- son algunas reglas, pautas para maximizar los rendimientos de cada uno, del Estado, de las empresas y de las organizaciones de la sociedad civil, en ese objetivo que nunca debemos perder de vista que es la mejora sensible de la calidad de vida de todos los uruguayos particularmente los más postergados".

En el Ministerio de Trabajo y Seguridad Social (MTSS) la cuestión de la responsabilidad de la empresa es uno de los temas de la próxima "Convocatoria al compromiso por el empleo, el ingreso y las responsabilidades". 


\section{f) La promoción de la igualdad de derechos y oportunidades entre hombres y mujeres}

La discriminación de género es una de las más importantes discriminaciones en los sistemas de relaciones laborales en el mundo. Ella es aún más importante en América Latina, donde existe una fuerte cultura machista.

El Parlamento uruguayo aprobó el 15 de marzo de 2007 la Ley $\mathrm{N}^{\circ} 18.104$ que encomienda al Estado "el diseño, la elaboración, la ejecución y el seguimiento de las políticas públicas" que aseguren la igualdad de derecho y oportunidades entre hombres y mujeres y que integren la perspectiva de género en toda actividad ciudadana. La ley además encomienda al Instituto Nacional de las Mujeres el diseño de un Plan Nacional de Igualdad de Oportunidades y Derechos que dé cumplimiento a los compromisos contraídos por el país en el ámbito internacional relativos a la no discriminación de las personas por razones de género.

\section{El Plan Nacional de Igualdad de Oportunidades y Derechos deberá:}

a) Garantizar el respeto y la vigilancia de los derechos humanos de las mujeres, conceptualizados como derechos civiles, políticos, económicos, sociales y culturales, aplicando y desarrollando una legislación igualitaria.

b) Promover la ciudadanía plena, garantizando el ejercicio igualitario de los derechos, la inclusión social, política, económica y cultural de las mujeres, así como su participación activa en los procesos de desarrollo.

c) Promover cambios culturales que permitan compartir en condiciones de igualdad el trabajo productivo y las relaciones familiares y aseguren el acceso equitativo de hombres y mujeres a los procesos de innovación, ciencia y tecnología en los planes de desarrollo.

Para que la ley no quede en el plano de los enunciados programáticos, se establece en su artículo final que "será obligatoria la rendición de cuentas anual ante la Asamblea General, respecto de los avances en la ejecución del Plan Nacional de Igualdad de Oportunidades y Derechos, a realizarse en el marco de las actividades del 8 de marzo, Día Internacional de la Mujer".

La reciente Ley No 18.868 de 23.12.2011 introduce una nueva tutela que busca proteger uno de los aspectos más importante de la mujer trabajadora: el derecho a ser admitida a un puesto de trabajo, ascender en la carrera funcional o permanecer en el empleo, sin tener que dar cuenta de la eventual situación de gravidez: en efecto la ley prohíbe:

"exigir la realización o presentación de test de embarazo o certificación médica de ausencia de estado de gravidez, como requisito para el proceso de selección, ingreso, promoción y permanencia en cualquier cargo o empleo, tanto en la actividad pública como privada. Asimismo se prohíbe la exigencia de toda forma de declaración de ausencia de embarazo". 
Juan Raso Delgue / El sistema uruguayo de relaciones laborales: entre autonomia y negociación

\section{g) La promoción de políticas sociales para personas y familias en estado de indigencia}

Una de las consecuencias de la crisis del año 2002/2003 fue el incremento de la marginalidad y la pobreza. A raíz de la situación general de precarización económica y social, el gobierno creó el Ministerio de Desarrollo Social (MIDES) con el objetivo de asistir a los sectores ciudadanos excluidos de toda protección social.

Entre las primeras medidas promovidas por el MIDES para contener la grave situación de indigencia generalizada, fue la adopción del plan PANES -Plan de Atención Nacional a la Emergencia Social-, que otorga un subsidio denominado "Ingreso Ciudadano" a aquellas personas y familias en situación de indigencia, es decir con ingresos que estén por debajo del valor promedio de la canasta básica alimentaria. En esta primera acción se asignaron subsidios a 79.000 familias (aproximadamente 300.000 personas, es decir el $10 \%$ de la población del Uruguay).

El plan pretende ir disminuyendo la carga de los subsidios e irlos sustituyendo con trabajos transitorios coordinados con las municipalidades, la Administración Nacional de Educación Pública y los diversos ministerios. Actualmente, se está discutiendo en el Parlamento un proyecto de ley que obliga a las empresas que se presenten en licitaciones públicas a contratar un cupo de personas amparadas por el Plan.

También se procura a través del PANES desarrollar proyectos comunitarios en las áreas locales para organizar trabajos cooperativos, de modo de restablecer vínculos con el sector formal de la economía.

\subsection{LOS EMPLEADORES}

En Uruguay, como en otros países del continente, coexisten viejos y nuevos modelos empresariales: por un lado, se expanden formas de producción que se remiten a criterios pretaylorista (trabajo negro sin protección laboral), por el otro, se implementan nuevas políticas de aprovechamiento de los "recursos humanos" (reestructuración de la empresa, tercerizaciones, etc.). Junto a la empresa multinacional convive la pequeña empresa, con específicas características: número reducido de trabajadores con vínculos familiares o personales (mismo barrio, origen social común, etc.), relaciones de solidaridad que se anteponen a la subordinación jurídica típica, capital limitado, tendencia a depender económicamente de unos o pocos adquirentes, que compran la totalidad de la producción. Renacen antiguas formas de trabajo asociado (cooperativas) que permiten abaratar costos laborales y fiscales. $\mathrm{Su}$ función sin embargo encubre muchas veces verdadero trabajo dependiente.

La negociación de los Consejos de Salarios ha favorecido las relaciones por sectores de actividad, así que no solo se han reforzado los respectivos sindicatos, sino también la Cámara empresariales, porque el sistema obliga a los empleadores a negociar agrupados por sectores.

En la confrontación negocial, los empleadores reclaman respeto y buena fe por parte del sindicato y consideran que el actual gobierno de tendencia izquierdista ha desequilibrado el sistema de relaciones laborales en favor de los trabajadores. Entre los temas que plantean en la negociación están los de la productividad, la organización del trabajo a través de funciones y competencias de los trabajadores, y no en base a las tradicionales categorías del industrialismo, la incorporación tecnológica y los consecuentes procesos de reestructuración 
de las empresas, pero también están dispuestos a negociar sobre condiciones de trabajo, condiciones ambientales e higiene laboral. El tema de la formación y capacitación no es percibido como uno de los puntos centrales para los intereses futuros del rediseño de nuevas áreas para la incorporación tecnológica, en el sector de la construcción hace 15 años que incorporamos la productividad al salario. Las condiciones de trabajo, la higiene laboral, son temas que los tenemos juntos hace mucho.

\subsection{LOS TRABAJADORES Y SUS ORGANIZACIONES}

Los trabajadores, luego de haber visto notablemente debilitadas sus organizaciones en el período 1992 a 2005 , han recompuesto su fuerza sindical, a partir precisamente del fuerte impulso que dieron la nueva convocatoria de los Consejos de Salarios y la aprobación de la Ley No 17.940 de Libertad sindical.

El cambio del contexto político-laboral ha promovido la creación de más de 600 nuevos sindicatos y los índices de afiliación -que con anterioridad al año 2005-oscilaban en el $10 \%$ de afiliados, hoy en muchos casos superan el $50 \%$. El rápido crecimiento y fortalecimiento de las organizaciones sindicales ha enfrentado viejas y nuevas "culturas y estrategias" de acción. Por un lado, es posible individualizar sindicalistas de vieja formación, cuyas estrategias de confrontación son a mediano plazo; por el otro, "nuevos sindicalistas" sin un grado importante de experiencia que exigen soluciones inmediatas a sus pedidos. También puede diferenciarse en la situación interna de los sindicatos, corrientes "oficialista" más favorables al gobierno, y corrientes radicales que se discrepan fuertemente con el gobierno. De todos modos, como veremos más adelante, todas ellas están reunidas en una única organización a nivel nacional: el PIT-CNT.

Si bien el nuevo marco normativo ha reconstruido el poder sindical, deben anotarse algunas causas endógenas y exógenas que pueden a mediano plazo debilitar la mayor fuerza actual del movimiento. Entre las primeras, debe a nuestro juicio señalarse la dificultad de una "modernización" del discurso y de las estrategias en un contexto económico, completamente diferente al de la década de los 60 y 70 . Las banderas de la "lucha obrera" y del "conflicto de clase" siguen agitándose en algunas organizaciones, en contraste con los intereses de sus representados y con la diferencialidad propia de la época: más varía el interés de los trabajadores individualmente considerados y más se debilita la solidaridad del grupo, que sigue siendo la base del poder sindical.

La segunda consideración es que el poder creciente del movimiento sindical uruguayo deriva más del apoyo recibido por el Gobierno, que de logros conseguidos a través de impulsos y conquistas propias. Esto no excluye que el sindicato pueda en su accionar futuro acumular "poder propio" a partir de las cuotas de poder que le ha otorgado el Estado.

\section{EL CONFLICTO Y LA NEGOCIACIÓN: LAS CARACTERÍSTICAS DEL MODELO}

\subsection{EL SISTEMA TRADICIONAL}

Si bien el sistema uruguayo de relaciones laborales ha experimentado a lo largo del siglo XX cambios importantes, es posible sin embargo destacar algunos aspectos, que a nuestro juicio aún hoy lo individualizan como un modelo con características propias, aunque el sistema está sufriendo algunas transformaciones importantes. 
Juan Raso Delgue / El sistema uruguayo de relaciones laborales: entre autonomia y negociación

Entre las tradiciones características del sistema, señalaremos:

Importante autonomía normativa en lo colectivo

El derecho colectivo del trabajo uruguayo está concentrado en pocas normas de alto rango (la Constitución, los Convenios Internacionales del Trabajo 87 y 98, los Pactos y Declaraciones internacionales). No existen, en cambio, normas legislativas que regulen los procedimientos de constitución de sindicatos o el instituto de la huelga. En materia de negociación colectiva, la ley existente se remite fundamentalmente a los criterios fijados por la OIT en la materia. La misma justicia del trabajo solo es competente para los "conflictos individuales", quedando al margen toda la conflictividad colectiva. Es decir, que es un sistema -en lo colectivo- completamente autónomo, donde son las partes quienes producen las normas y las prácticas que regulan su relacionamiento.

La misma Ley 17.940 sobre libertad sindical, no ingresa a regular aspectos vinculados a la organización sindical, la huelga o la negociación colectiva.

Sin perjuicio de lo expresado, es intención del Ministerio de Trabajo y Seguridad Social presentar al parlamento un proyecto de ley para regular diversos aspectos de la negociación colectiva, porque la ausencia regulatoria produce inseguridad en los negociadores.

\section{b) Organización sindical única en un modelo de pluralidad sindical}

El sistema sindical uruguayo se inscribe en un modelo de pluralidad sindical. La no existencia de normas permite una amplia coexistencia de organizaciones sindicales. Es más: el art. 57 de la Constitución, al afirmar que la huelga es un derecho "gremial", reconoce aun aquellas organizaciones precarias y sin estructuras formales como son las meras agrupaciones o gremios. Sin embargo desde 1964 los trabajadores se reconocen en una única central sindical -el PIT/CNT- que en casi cuatro décadas ha sido la única organización de cúpula que ha nucleado los trabajadores privados y públicos. Por lo tanto, se concluye que si bien el modelo permite la convivencia de diversas centrales sindicales, existe de hecho una organización sindical única reconocida por todos los sindicatos a nivel de actividad y de empresa.

\section{c) Negociación colectiva por rama de actividad}

La experiencia de los Consejos de Salarios desarrolló a partir de la década del 40 el sindicalismo por rama de actividad: como hemos dicho, en los Consejos de acordaban los salarios mínimos por grupos de actividad (la actividad privada del país estaba dividida en aproximadamente 50 grupos). Esta realidad determinó el desarrollo de un derecho colectivo del trabajo focalizado fundamentalmente a nivel de rama de actividad. En la actualidad la nueva convocatoria de los Consejos de Salarios ha reforzado el poder sindical a nivel de rama, puesto que en dichos Consejos la negociación es siempre por sectores de actividad.

\section{d) Importancia de la doctrina nacional}

En el Uruguay, las doctrinas generalmente admitidas son fuente supletoria de derecho con rango constitucional (art. 332 de la Constitución). Como ya indicáramos, en el sistema normativo laboral asume especial relevancia esta fuente. Muchos de los conceptos y reglas jurídicas que regulan el sistema son de origen doctrinario. La destacada doctrina nacional, 
que reconoce su iniciador en De Ferrari y sus mayores exponentes en los juslaboralistas Barbagelata y Plá Rodríguez, ha influenciado notoriamente en el ámbito normativo. La elaboración de los principios del derecho del trabajo, así como la determinación de conceptos centrales como los de salario, notoria mala conducta, poder disciplinario, jus variandi, etc. han sido todos ellos de creación doctrinaria.

\section{e) Importancia emergente de la jurisprudencia}

En los últimos años ha adquirido mucha importancia como fuente de derecho la jurisprudencia nacional. Mientras que hasta la década de los 80 , la jurisprudencia se limitaba a recoger la doctrina más prestigiosa, hoy los jueces intervienen con mayor protagonismo en la definición de sus fallos. Han contribuido a ello dos factores de naturaleza muy diferente: a) por un lado, los significativos cambios del mundo del trabajo han enfrentado los jueces a problemas nuevos, muchas veces no regulados por normas expresas y con opiniones doctrinarias contradictorias; b) por otra parte, ha sido la misma doctrina uruguaya que a través de la regular publicación de las sentencia judiciales en los Anuarios de Jurisprudencia Laboral ha difundido el conocimiento de las sentencias judiciales. Podemos por lo tanto afirmar que la regulación de las relaciones laborales tiene hoy una importante base jurisprudencial, próxima a los criterios anglosajones, donde el juez no solo aplica, sino crea el derecho.

\subsection{EL SISTEMA EMERGENTE DE LA LEY No 18.566 DE 11.9.2009}

El tradicional modelo autónomo uruguayo de relaciones laborales -y en especial de negociación colectiva- ha sido en parte modificado a partir de la Ley No 18.566.

En el modelo tradicional era posible distinguir en el Derecho del trabajo dos vertientes: la estatal o heterónoma en el derecho individual del trabajo, que expresaba la intensa intervención protectora del Estado y, por el otro, la vertiente de la autonomía en los que respecta al derecho colectivo del trabajos. En este marco se desarrolló una amplia negociación colectiva pura o informal, no regulada, de surgimiento espontáneo y curso discontinuo, impuesta casi siempre por el conflicto y la reivindicación sindical6. Hablábamos de negociación colectiva "típica", para diferenciarla del sistema nacido en el año 1943, que se expresó en una negociación estructurada por grupos de actividad en el ámbito de los Consejos de Salarios (con las consabidas suspensiones en los años 1968 a 1985 y 1992 a 2005). Las dos modalidades de negociación -informal/bipartita y orgánica/tripartita- operaron contemporáneamente en los períodos de convocatoria de los Consejos de Salarios, mientras en las épocas en que estos no fueron convocados, siguió operando la negociación colectiva informal. Esta estructura separada y a la vez complementaria, permitió expresar a Bronstein que en Uruguay existía un sistema de negociación de "doble pista"”.

\footnotetext{
5 Rosenbaum, J., Ameglio, E. y Raso, J. "Intervención y autonomía en las relaciones colectivas de trabajo en Uruguay", en: ERMIDA URIARTE, O., en: AA. VV., Intervención y Autonomía en las Relaciones Colectivas de Trabajo. Uruguay, Montevideo, 1993 , p. 275

$6 \quad$ Ibid., p. 296.

7 BRONSTEIN A. "La evolución de las relaciones de trabajo en el Uruguay: logros y desafíos", en: Revista Internacional del Trabajo, vol. 108, Ginebra 1989, p. 92.
} 
En este modelo en el que convivieron tradicionalmente una negociación no estructurada y autónoma y la experiencia de los Consejos, se aprobó -luego de un intenso debate político, jurídico y mediático- la Ley No 18.566 promulgada el 11.9.2009. Sus orígenes se remontan a la plataforma política de la coalición Frente Amplio-Encuentro Progresista, que alcanzó el gobierno en marzo de 2005. En la misma se establecían tres objetivos concretos en materia laboral: a) la convocatoria de los Consejos de Salarios; b) una ley de protección de la libertad sindical; c) una ley de negociación colectiva. Cumplida la convocatoria de los Consejos en los primeros meses de 2005 y aprobada la ley de libertad sindical el 2 de enero de 2006, quedaba pendiente la cuestión relativa a la regulación de la negociación colectiva.

Ese modelo tradicional y regulado con relación a la negociación colectiva bipartita convivió a lo largo de más de seis décadas con el sistema de Consejos de Salarios. La negociación bipartita y la negociación tripartita de los Consejos (con excepción de los períodos de ausencia de convocatoria) compartieron un espacio común en el sistema de relaciones laborales nacional, pero operar desde perspectivas distintas: funcionaron como buenos vecinos, cada uno identificado en un domicilio propio.

La ley No 18.566 intervino en el modelo tradicional y provocó sustanciales cambios, cuyas consecuencias vamos reconociendo de a poco. Señalaremos dos aspectos importantes:

a) La Ley No 18.566 interviene con decisión en el sistema jurídico de relaciones laborales y lo hace a partir de la idea que la negociación orgánica de los Consejos de Salario es la negociación por excelencia, a la que se subordina la contratación colectiva bipartita. Ya no es posible hablar de autonomía colectiva en los términos amplios en que la más prestigiosa doctrina nacional (Plá Rodríguez, Barbagelata, Ermida Uriarte, Rosenbaum, etc.) lo hicieron con anterioridad al año 2009. La autonomía aún existe, es cierto, pero ha perdido el voltaje que tenía en el pasado. Hoy el sistema opera en un sistema que oscila entre la autonomía y la heteronomía, entre la voluntad de las partes, y las reglas del Estado, que ponen límites a esa voluntad.

b) Los cambios que introduce la Ley No 18.566 ponen fin a la relación de buena vecindad entre los convenios colectivos bipartitos y la negociación tripartita y establecen un sistema de domicilio único para ambas. La tradicional negociación bipartita ya no es una de las dos "pistas" de la negociación uruguaya, con características propias, porque la ley establece cambios que trasladan esta al carril de la negociación estructurada de los Consejos. Una desapasionada lectura de la ley lleva a la conclusión que la negociación colectiva está en un escalón más bajo que la negociación en los Consejos de Salarios, aquella actúa con cierta dependencia de lo que estos decidan.

Siguiendo uno de los simil que hemos empleado, la nueva negociación colectiva opera hoy a tres niveles, siendo que el nivel más importante es ocupado por la que se desarrolla a nivel de los Consejos de Salarios, siguiéndole la negociación bipartita por actividad y, por último, la negociación por empresa. El legislador, al aprobar la Ley No 18.566, reconoce como principal estructura negocial de nuestro sistema a los Consejos, con la idea subyacente que estos han forjado la identidad del sistema de relaciones laborales, reportando los mayores efectos positivos sobre un modelo laboral que promueve las tutelas laborales. 


\section{UNA LEGISLACIÓN QUE AMPLÍA LAS TUTELAS LABORALES}

Debemos también señalar que, a diferencia de lo que ha acontecido en otros países donde se han profundizado criterios de flexibilidad laboral, en Uruguay los últimos años han visto la reconstrucción de un modelo de Estado de bienestar social, apuntalado en diversas leyes ampliamente protectorias.

Entre ellas destacamos:

- Ley No 18.065 de 27.11.2006 que dicta normas sobre el trabajo doméstico y en especial fija en 44 horas semanales y 8 diarias el límite de la jornada de este tipo de trabajo;

- Ley No 18.091 de 7.1.2007 que amplía a cinco años la prescripción de los créditos laborales;

Leyes $\mathrm{N}^{\circ} 18.099$ de 24.1.2007 y No 18.251 de 6.1.2008 que establecen normas para la protección de los trabajadores ante los procesos de descentralización empresarial;

- $\quad$ Ley 18.441 de 22.12.2008, que limita a 8 horas la jornada del trabajador rural;

- Ley No 18.561 de 11.9.2009 sobre acoso sexual en el trabajo y en la relación docente;

- $\quad$ Ley No 18.572 de 13.9.2009 que abrevia los procesos laborales y establece tutelas para el trabajador en la etapa del procedimiento de reclamo de créditos laborales.

\section{EL DESAFÍO ACTUAL: DE LA CONFRONTACIÓN A LA PARTICIPACIÓN}

Las organizaciones de empleadores y trabajadores en Uruguay enfrentan el desafío de adaptarse a un nuevo sistema de relaciones laborales, en el que aparecen formas diferentes de gestión empresarial en un entorno económico, marcado por la extrema competencia generada por la internacionalización creciente de la economía. A ello se suman los cambios, casi permanentes, de las técnicas de producción y de comunicación, que requieren nuevas competencias por parte de los trabajadores y una rápida adaptación a los cambios.

En este contexto, los actores deben adaptarse a mercados más abiertos, más competitivos, a una organización de la producción y de los servicios a la vez más compleja, más segmentada y remodelada por nuevas técnicas, para lograr representar eficientemente no solo sus respectivos intereses, sino a los intereses de la sociedad en su conjunto, como medio genuino de cohesión social y progreso económico.

En este nuevo panorama, las relaciones laborales están destinadas a jugar un rol cada vez más importante en la conducción de los cambios, que es el desafío básico dirigido hoy en día a los sistemas sociopolíticos de todos los países avanzados: los actores sociales tienen la responsabilidad conjunta de aumentar el potencial económico de la comunidad a través del crecimiento de la productividad, el empleo sostenible y el desarrollo completo de la sociedad basada en el conocimiento. Esta ambiciosa variedad de responsabilidad requiere que el sistema de relaciones laborales sea no solo una institución dependiente reaccionando a factores externos (tecnológicos, económicos), sino un actor sociopolítico de pleno derecho. 
Ante estas comprobaciones que parecen bastante obvias, seguimos sin embargo observando marcadas resistencias en el ámbito laboral de parte de los actores del sistema (¿pocos o muchos sindicatos y cámaras?) más interesados en la presión y en la confrontación, que en asumir responsabilidades conjuntas.

La pregunta clave que planteamos y nos planteamos es: ¿podemos concebir un modelo uruguayo de relaciones laborales más participativo y menos confrontativo? ¿Podemos generar cambios cualitativos en el proceso de negociación que vuelvan socialmente responsable a empresas y sindicatos en su recíproco relacionamiento?

No es fácil contestar en forma positiva a estos planteos a partir de una realidad que históricamente se ha diferenciado en el contexto latinoamericano precisamente por su alto grado de confrontación. Tampoco nos resignamos a una contestación negativa. Preferimos pensar que es posible una contestación positiva en la medida que entendamos que la misma constituye necesariamente un "proceso de construcción" en el sistema de RRLL uruguayo. Este proceso de construcción debe emprenderse a partir de algunos propósitos comunes, que posibiliten conformar una nueva cultura que privilegie la participación sobre la confrontación. Tres son básicamente a nuestro juicio los caminos para cumplir con el propósito:

1. La ampliación de la materia de la negociación;

2. El estímulo de nuevos espacios de autonomía que permitan a las partes la búsqueda de nuevos consensos;

3. La profesionalización de las relaciones laborales.

Entre los posibles objetivos de una negociación más participativa un rol importante debe atribuirse a la cuestión de la perdurabilidad de la fuente de trabajo y el respeto del medio ambiente. Es evidente que estos objetivos, poco transitados en la discusión de los Consejos de Salarios son particularmente indicados para promover una negociación que comprometa a ambos actores. La perdurabilidad de la fuente de trabajo es para el trabajador garantía de una verdadera estabilidad laboral, mientras que asegura a la empresa trabajadores involucrados en su proceso productivo. Pero la continuidad de la fuente de trabajo es posible en la medida que se instrumenten procesos formativos de los trabajadores que acompañen los cambios tecnológicos. Es necesario asegurar una verdadera formación en la empresa, a través de sistemas de formación continua capaz de acompañar los recorridos de movilidad y de reconversión del trabajo, que permitan en definitiva volver compatibles la flexibilidad en la seguridad. Por otra parte, la formación es un objetivo prioritario para las partes en la medida que por un lado se vincula a la mejora de la calidad y de la productividad y, por la otra, con la decencia y dignidad del trabajo: una mayor formación asegura trabajos de mejor calidad.

Con respecto del medio ambiente y las condiciones de salud del trabajador es necesario en primer lugar promover el conocimiento sobre estos temas tan esenciales para todos aquellos (empleadores y trabajadores) que comparten el lugar de trabajo. Es importante "aprender a conocer" el medio ambiente, porque aunque a todos nos gusta hablar del "Uruguay Natural", poco sabemos sobre el ambiente y no logramos construir a nivel de ciudadanía una cultura ambientalista. Experiencias en otros países del mundo han demostrado im- 
portantes avances en la promoción del medio ambiente y de la salud en la empresa a través de acuerdos entre empleadores y trabajadores para realizar mapeos de los lugares de trabajo. Son precisamente los que trabajan en determinado lugar quienes mejor pueden determinar las zonas y elementos de peligro presentes en el mismo.

Es necesario agregar nuevos espacios de negociación. Entre ellos destacamos:

La participación. ¿Es posible en nuestro sistema apostar a una conducción más participativa de la empresa? Evidentemente en la lógica de la empresa fordista la participación representaba un cuerpo extraño y eso ha sido evidente en las relaciones de los actores nacionales particularmente anclados a las formas de relacionamiento del modelo fordista. La participación no solo ha sido negada por los empleadores -que han visto en ella una resignación de su poder de dirección y conducción de la empresa-, sino también por el sindicato que históricamente ha mirado con desconfianza hacia la participación, precisamente por considerarla una modalidad de conducta en contraste con una concepción clasista y confrontativa de las relaciones laborales.

Sin embargo, hoy las crecientes exigencias de calidad y de contención de los costos, incluidos los de transacción, empujan las empresas a buscar que los trabajadores estén más involucrados. Por otra parte, el creciente grado de instrucción de los trabajadores contribuye a aumentar la necesidad y las potencialidades de la participación, en distintas formas gestionales y económicas, desde los premios de productividad al accionariado de los trabajadores. "Este es por lo tanto un terreno de elección para una nueva normativa promocional. Pero esta vía será transitable en la medida que las partes sociales manifiesten una efectiva disponibilidad de hacerlo". Los intentos enfrentan las resistencias y desconfianza fuertemente presentes en la tradición sindical, que consideran formas de cogestión "a la alemana" limitantes para la identidad de la acción sindical. Sin embargo recuerda el relacionista italiano que las pistas brindadas por la Directiva sobre la Sociedad Europea (SE) son valiosas y han abierto una posibilidad de acuerdo entre las partes del todo nueva. La vía negocial puede permitir adaptar la normativa a las sensibilidades (y también a las idiosincrasias) de nuestras partes sociales. Experimentaciones, si bien limitadas, de formas participativas en la empresa pueden ser útiles ya sea para el sindicato que para las empresas y constituir además un factor útil para balancear las incertidumbres a las cuales están expuestos los trabajadores, subordinados y no, a causa de la de los mercados y de la flexibilidad de los trabajos.

El tiempo de trabajo. Nuestra legislación es extremadamente rígida en materia de tiempo de trabajo. También en este caso la regulación del tiempo de trabajo está pensada en base a un modelo taylorista, que hoy tiende a desaparecer. El tiempo de trabajo - así como sucede en Francia y otros países europeos - puede ser objeto de negociación: pensemos en ejemplos sobre anualización del tiempo de trabajo o en convenio que ya operar en el país (Fábrica Nacional de Cervezas, marina mercante) donde las normas convencionales se apartan de las rigideces legales. 
El cambio y la competitividad. La cogestión del cambio. La competitividad depende de factores exógenos (precios internacionales, inflación, tipo de cambio, crecimiento de la actividad económica, etc.) y endógenos (gerenciamiento, productividad, conflictividad, capacitación suficiente, etc.). Hoy no es posible ser competitivos sin la tecnología, la inversión y el gerenciamiento adecuado; pero tampoco es posible sin el compromiso, la capacitación y la responsabilidad en el trabajo.

Otro temas sobre lo que es posible negociar desde una perspectiva "ganar-ganar" -pero ya no nos da el tiempo en nuestra exposición y solo indicamos los titulares- son negociar por funciones y no por categorías, acordar premios individuales y de grupo, promover normas sobre igualdad entre grupos fuertes y débiles (jóvenes, mujeres, sujetos discriminados), consensuar reglas y mecanismos de enfriamiento del conflicto

Con relación a la negociación colectiva pensamos que debe fortalecerse una cultura que vea en la negociación el mejor instrumento de adecuación de las condiciones laborales. Hay que rescatar la autonomía negocial de las partes: hacia una flexibilidad regulada y negociada del mercado de trabajo.

No hay además que temerle a la negociación de empresa, cuando en el país están dadas adecuadas reglas de libertad sindical. Tiziano Treu, ex Ministro de Trabajo de la izquierda Italiana, ha dicho hace dos años que "hay que dar mayor espacio a la contratación a nivel de empresa, porque esta es capaz de adecuar mejor las condiciones de trabajo a la situación de la empresa y de negociar retribuciones de productividad".

Para las pequeñas empresas, hay que pensar en formas de negociación territorial (ejemplo, departamentos). No es realista pensar defenderla en modo uniforme desde el centro de los sistemas productivos que se están cada vez más diferenciando y descentralizando.

La exigencia de mayor autonomía y personalización en las relaciones de trabajo subordinado es una de las señales más en los nuevos órdenes productivos y tiene que ver con muchos aspectos de la organización del trabajo, de los horarios y de la retribución.

Finalmente es necesario profesionalizar las relaciones laborales en un doble sentido: a) Profesionalizar el gerenciamiento, porque la contribución de los trabajadores, su actitud y motivación es un elemento también crítico para el éxito de la empresa; b) Profesionalizar a los negociadores del sistema. No es posible que en situaciones de extremo conflicto son las mismas partes que tratan de componerlo. Más que emoción y "sentido de la lucha", se necesita serenidad y conocimientos para resolver un conflicto.

En este marco de relaciones laborales el Estado está también llamado a cumplir un rol importante. Entre las obligaciones del Estado señalo: el poder público tiene el deber de quitar los obstáculos al desarrollo, alivianando los pesos de la burocracia -especialmente aquella vinculada directamente con la producción y la exportación- y sostener la innovación y la investigación, también en el sistema industrial. Además, el Estado sigue teniendo una importante asignatura pendiente en materia de educación y la formación

Es necesario comprender la necesidad de juntar fuerzas (laborales y empresarias), para afrontar de forma más eficiente y eficaz la competencia internacional, teniendo en cuenta que el mejor resultado de una negociación es aquel del que todas las partes salen ganando. Los sindicatos y los empresarios deben aprender a concurrir juntos en la negociación inter- 
nacional, presentándose no como dos fuerzas de producción (trabajo y capital) contrapuestas, sino como una única fuerza productiva, en búsqueda del desarrollo económico del país.

\section{CONCLUSIONES}

Del examen de lo expresado hasta ahora, surge un cuadro de fortalezas y debilidades del sistema de relaciones laborales de Uruguay, que nos permitirá extraer algunas conclusiones.

Entre las principales fortalezas, podemos señalar:

a) Un adecuado nivel cultural en los actores sociales, que ha distinguido al país durante más de un siglo en el contexto latinoamericano y que ayuda a manejar un lenguaje común en la administración del sistema.

b) Una tradición de diálogo social construido sobre estructuras tripartitas que remontan a la década de 1930. La administración de la seguridad social, la Junta Nacional de Empleo, la negociación salarial en el ámbito de los Consejos de Salarios y muchas otras instituciones constituyen la expresión de una cultura profundamente arraigada en el país sobre la conveniencia de la participación de los actores en todo lo relativo al sistema.

c) Una reactivación de los niveles de tutela de los trabajadores ya sea a nivel individual que sindical a partir del año 2005: en especial la protección sindical introducida con la Ley 17.940 aparece como un elemento esencial para asegurar el diálogo social entre los tres actores (Estado, empleadores y trabajadores) en pie de igualdad, requisito indispensable para un diálogo efectivo y comprometedor.

Entre las principales debilidades, señalamos:

a) Pese a los avances en materia de estructuras que favorecen el diálogo social, sigue existiendo un clima de fuerte confrontación entre los actores, que se visualizan como partes antagónicas en un juego de poder que alterna el conflicto con la negociación. Las estrategias negociales de las partes responden generalmente a un modelo de tipo competitivo (ganar/perder) y no de tipo cooperativo (ganar/ganar) ${ }^{8}$.

b) Si bien existe un aceptable nivel cultural a nivel de población en general, se observa una importante desconexión entre el sistema formal de educación y las necesidades reales del mercado de trabajo. La enseñanza -típicamente académica y teórica- sigue formando para trabajos que son considerados "destacados" en la cultura del país (formación universitaria tradicional, magisterio, trabajo bancario), mientras no hay suficiente mano de obra para nuevas necesidades del mercado (nuevas tecnologías, forestación, marina mercante, etc.). En ese contexto se señala la desvaloración de la Universidad del Trabajo (UTU), que es el instituto de formación técnico-profesional

8 Cedrola G. "El debate internacional actual sobre las relaciones de trabajo. Enfoques y teorías contemporáneas", en: Revista Relaciones Laborales $\mathrm{n}^{\circ} 4$, abril 2004, Montevideo, p. 11. 
del país, y que podría ser un instrumento importante para adecuar la capacitación profesional a los requerimientos del mercado.

c) Con relación a las políticas de empleo y si bien la experiencia de la JUNAE antes y el INFOP después, han significado un foro de acuerdos tripartitos en materia de empleo, los resultados de su labor no han sido importante y los niveles de empleo responden más a las coyunturas económicas favorables o desfavorables, que a una planificación concertada en la materia.

d) La negociación colectiva es pobre en materia de competitividad y entre los temas que exigen profundización están los de la productividad, la organización del trabajo a través de funciones y competencias de los trabajadores, y no en base a las tradicionales categorías del industrialismo, la incorporación tecnológica y los consecuentes procesos de reestructuración de las empresas, la formación, las condiciones ambientales e higiene laboral.

e) Para conseguir resultados importantes en materia de diálogo social y competitividad es necesario formar negociadores capacitados, en representación de los tres actores sociales, que permitan "profesionalizar" las relaciones laborales. En este sentido, los empresarios han promovido escuelas de relaciones laborales (especialmente en las Universidades privadas), mientras las organizaciones sindicales comienzan a organizar cursos de formación ya sea en forma autónoma o en cooperación con la enseñanza terciaria.

La conclusión es que el sistema de relaciones laborales tiene por un lado instrumentos y mecanismos que promueven el tripartismo y el diálogo social, pero por el otro se presenta como un sistema de confrontación, en la medida que los actores priorizan el conflicto como elemento clave de interrelación, siendo la negociación colectiva puramente instrumental al mismo. Las instancias de fuerza preceden generalmente la negociación, a divergencias de los sistemas de consenso o de cooperación, en los que el conflicto desarrolla un rol secundario?. Esta intensa confrontación persiste pese a que el actual gobierno es ideológicamente afín al movimiento sindical y ella paradójicamente se profundiza en el sector público. Entre las características que sustentan estas relaciones de conflicto deben indicarse la ausencia de una cultura de la tolerancia como uno de los valores esenciales en el desarrollo del sistema ${ }^{10}$. Con el nuevo impulso dado a las relaciones laborales en el año 2005 se crearon aproximadamente 500 nuevos sindicatos que se suman al sindicalismo tradicional. Los nuevos sindicatos, con dirigentes también nuevos y poco experimentados, ingresan en el sistema con una gran fuerza reivindicativa y muchas veces con estrategias agresivas (ejemplo, la ocupación de las fábricas) que introducen un nuevo elemento de tensión en un sistema confrontativo. En este contexto no podemos aún evaluar el rol y la complejidad del nuevo sindicalismo de la policía, que pretende tener derechos de acción similares a las otras organizaciones sindicales.

9 Sobre la clasificación que distingue entre sistemas de consenso, sistemas de confrontación y sistemas de consenso mitigado, ver MOLITOR, M. Relations Industrielles. Lovaina, Bélgica: Université Catholique de Louvain, 1993, citado por CEDROLA G., op. cit., p. 12.

10 Cedrola G., op. cit. (n. 8.). 
En este contexto el Estado uruguayo juega, como en muchos países de América Latina, un papel mucho más importante que en los sistemas de relaciones laborales europeos o anglosajones, siendo muchas veces el destinatario de las reinvindicaciones sindicales de los trabajadores a los efectos de intentar consagrar aspiraciones, que de otra forma, no podrían alcanzar sin su intervención ${ }^{11}$.

Es también necesario reforzar en los actores sociales los principios de la transparencia y la confianza, que constituyen principios rectores del relacionamiento al interno de la empresa. Transparencia significa rendir cuentas con información veraz y la confianza nace del conocimiento y apreciación del comportamiento responsable del otro. Transparencia y Confianza son fundamentales en la construcción de un camino conjunto porque es necesario comprender que sin empresa no hay trabajadores, y a su vez sin trabajadores no hay empresa $^{12}$.

Con respecto a la ampliación de la materia negocial, es necesario promover un modelo cooperativo de relacionamiento pasa por la negociación de convenios "ganar-ganar", en que ambas partes puedan sacar provechos de sus recíprocas concesiones. Para ello es necesario ampliar el marco de la negociación, aplicar la creatividad de los actores para ubicar espacios y objetivos nuevos, que logren superar la lógica de la negociación limitada básicamente a la temática salarial.

Es necesario que existan negociadores con mayores conocimientos e idoneidad para la negociación, con formación en contenidos y en experiencia de otros países, con mayor creatividad para obtener salidas posibles cuando las salidas son difíciles y cuando la crisis impide soluciones fáciles. Hay que aprender a saber que las conductas negociadoras requieren respeto recíproco y claridad de objetivos ${ }^{13}$.

Por lo tanto, la formación debe comprender el aprendizaje de competencias que permitan mejores aptitudes para el diálogo y la negociación y al mismo tiempo permitan hacer comprender a los cuadros empresariales y sindicales la necesidad de juntar fuerzas (laborales y empresarias), para afrontar de forma más eficiente y eficaz la competencia internacional, teniendo en cuenta que el mejor resultado de una negociación es aquel del que todas las partes salen ganando. Los sindicatos y los empresarios deben aprender a concurrir juntos en la negociación internacional, presentándose no como dos fuerzas de producción (trabajo y capital) contrapuestas, sino como una única fuerza productiva, en búsqueda del desarrollo económico del país.

\footnotetext{
11 Al respecto puede verse CóRdova, E. Las Relaciones Colectivas del Trabajo en América Latina. Ginebra, Suiza: Organización Internacional del Trabajo, 1981. ERMIDA URIARTE, O. "Origen, características y perspectivas", en: La negociación colectiva en América Latina. Instituto Europeo de Relaciones Industriales, 1993 y Lucena, H. "Papel del Estado en las relaciones industriales en América Latina", en: Industrial relations/ Relations Industrielles, vol. 44, no 1, 1989, citado por CEDROLA G., op. cit. (n. 8.), pp. 12 y 13.

12 Vidal J. "Relaciones Laborales: de la confrontación a la participación" (2० foro de ACDE), julio de 2008, en: Revista Relaciones Laborales $\mathrm{n}^{\circ} 17$, agosto de 2008 .

13 Pérez del Castillo, S. "Relaciones Laborales, un Desafío País: del Conflicto a la Cooperación". Coloquio realizado en la Liga de Defensa Comercial, en: Revista Relaciones Laborales nº 15, diciembre de 2007.
} 